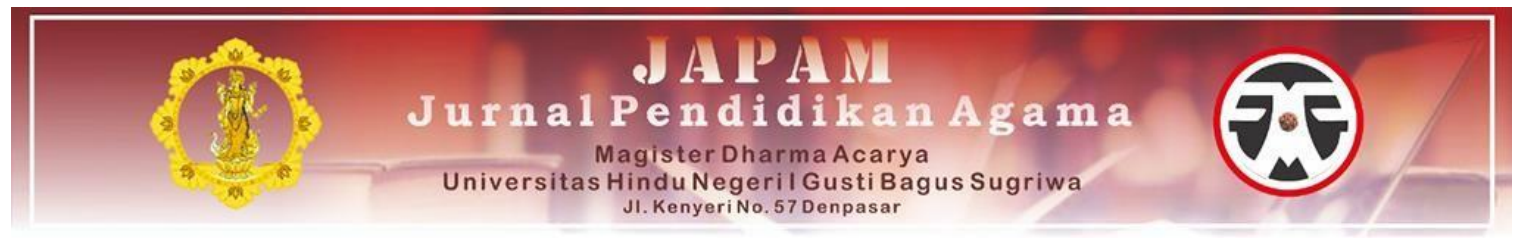

\title{
RELEVANSI PEMIKIRAN FILOSOFIS KI HADJAR DEWANTARA TERHADAP SISTEM PENDIDIKAN HINDU
}

\author{
Oleh: \\ Gede Agus Siswadi \\ Universitas Hindu Negeri I Gusti Bagus Sugriwa Denpasar \\ e-mail: gedeagussiswadi@gmail.com
}

Diterima: 29 Juli 2021, Direvisi: 25 Agustus 2021, Diterbitkan: 18 Oktober 2021

\begin{abstract}
Abstrak
Artikel ini berupaya untuk menelisik pemikiran Ki Hadjar Dewantara yang merupakan bapak pendidikan nasional. Dengan konsep pendidikan melalui "Tripusat Pendidikan" diantaranya keluarga, sekolah dan masyarakat. Selain itu konsep "Trilogi” yang beliau sampaikan mengenai ing ngarso sung tulada, ing madya mangun karsa dan tut wuri handayani. Metode yang digunakan dalam penelitian ini adalah metode deskriptif kualitatif dengan pengamatan sumber-sumber bacaan. Hasil penelitian ini menjelaskan tentang dasar dari pendidikan dan pengajaran Ki Hadjar Dewantara bersumber dari panca dharmanya. Dasar-dasar tersebut adalah: (1) kemanusiaan, (2) kodrat hidup, (3) kebangsaan, (4) kebudayaan, dan (5) kemerdekaan/ kebebasan. Metode belajar yang diusung oleh Ki Hadjar Dewantara adalah metode among. Among memiliki makna menjaga kelangsungan hidup batin peserta didik dengan mendampingi dan mengarahkan. Bukan hanya membiarkan perkembangan batin peserta didik namun juga menjaga agar keadaan batin peserta didik tetap dalam keadaan baik. Konsep pendidikan yang disampaikan oleh Ki Hadjar Dewantara memiliki relevansinya dengan konsep pendidikan yang terdapat dalam Hindu seperti jenjang pendidikan pada anak, konsep aguron-guron, mendidik karakter anak serta teks-teks pada kitab suci veda yang menjelaskan tentang sistem pendidikan Hindu.
\end{abstract}

Kata kunci: Pemikiran Ki Hadjar Dewantara, Pendidikan Hindu

\begin{abstract}
This article seeks to examine the thoughts of Ki Hadjar Dewantara who is the father of national education. With the concept of education through the "Tricenter of Education" including family, school and community. In addition, the concept of "Trilogy" that he conveyed was about ing ngarso sung tulada, ing madya mangun karsa and tut wuri handayani. The method used in this study is a qualitative descriptive method by observing reading sources. The results of this study explain the basis of Ki Hadjar Dewantara's education and teaching sourced from his five dharmas. These basics are: (1) humanity, (2) the nature of life, (3) nationality, (4) culture, and (5) independence/freedom. The learning method promoted by Ki Hadjar Dewantara is the among method. Among has the meaning of maintaining the inner survival of students by accompanying and directing. Not only
\end{abstract}


allowing the inner development of students but also keeping the inner state of students in good condition. The concept of education presented by Ki Hadjar Dewantara has relevance to the concept of education contained in Hinduism such as the level of education for children, the concept of aguron-guron, educating children's character and texts in the Vedic scriptures that explain the Hindu education system.

Keywords: Thoughts of Ki Hadjar Dewantara, Hindu education

\section{PENDAHULUAN}

Berbicara tentang pendidikan akan menjadi hal yang substansi dalam perkembangan manusia. Hal tersebut dikarenakan pendidikan merupakan hal yang amat penting bagi manusia dalam segala aspek kehidupannya. Pendidikan memberi pengaruh yang besar bagi manusia agar mampu bertahan hidup dengan membangun interaksi yang baik dengan sesamanya sehingga kebutuhan hidupnya terpenuhi dengan mudah. Idealnya, pendidikan sudah diberikan sejak dini supaya nilai yang ada di dalam pendidikan tersebut semakin mudah diterapkan di usia dewasa. Menurut Neolaka (2017: 2) menjelaskan kegiatan pendidikan adalah banyak cakupannya dan sangat berkaitan dengan perkembangan manusia muda, mulai dari perkembangan jasmaniah dan rohaniah, antara lain perkembangan fisik, pikiran, perasaan, kemauan, kesehatan, keterampilan, sosial, hati nurani, kasih sayang.

Pendidikan adalah kegiatan membudayakan manusia muda atau membuat orang muda ini hidup berbudaya sesuai standar yang diterima oleh masyarakat. Pendidikan menurut Undang-Undang Sistem Pendidikan Nasional No. 20 Tahun 2003 adalah usaha sadar dan terencana untuk mewujudkan suasana belajar dan proses pembelajaran agar peserta didik secara aktif mengembangkan potensi dirinya untuk memiliki kekuatan spiritual keagamaan, pengendalian diri, kepribadian, kecerdasan, akhlak mulia, serta keterampilan yang diperlukan dirinya dan masyarakat.

Sebagian besar masyarakat mengetahui bahwa konsep pendidikan yang dianut oleh Indonesia sebenarnya merupakan hasil pemikiran Ki Hadjar Dewantara (KH Dewatara), sehingga beliau pun dijuluki sebagai "Bapak Pendidikan Nasional" karena jasa yang sudah beliau berikan. Selain dikenal sebagai pendidik yang hebat, beliau juga terkenal sebagai orang yang agamis serta santun meski berasal dari kalangan ningrat. Sejak tahun 1935 dalam era kolonial, Ki Hadjar Dewantara telah mengemukakan pendapatnya mengenai Tripusat Pendidikan, yaitu keluarga, sekolah dan masyarakat. Menurut Ki Hadjar Dewantara masing-masing pusat pendidikan tersebut mempunyai tujuannya yang khas, namun tetap berhubungan satu dengan yang lainnya. Konsep Tripusat Pendidikan atau Trisentral Pendidikan sesuai dengan era kolonialisme mempunyai arti yang spesifik yaitu menentang sistem pengajaran kolonial (Tilaar, 2015: 16).

Berkaitan dengan sistem pendidikan menurut ajaran Hindu yang sesungguhnya tidak dapat dilepaskan dengan konsepsi Catur Asrama, sebagai empat tahapan hidup manusia, yaitu Brahmacari, Grahastha, Wanaprastha dan Bhiksuka (Sanyasin). Konsep Catur Asrama juga menjadi landasan konsepsional penerapan ajaran Hindu guna tercapainya tujuan hidup. Catur Asrama berasal dari kata catur yang artinya empat, dan asrama yang artinya tahapan/lapangan/usaha seseorang. Catur Asrama adalah usaha yang mutlak harus 
dilakukan oleh seseorang pada tiap-tiap tahapan hidup/asrama (Wiana, 1997: 53). Segala usaha yang harus dilakukan pada masing-masing asrama sangat berbeda-beda, hal ini sesuai dengan unsur Catur Purusartha yang ingin dicapai pada tiap-tiap asrama. Catur Purusartha adalah empat tujuan hidup manusia, yaitu Dharma, Artha, Kama dan Moksa (Wiana, 1997: 53).

Berangkat dari uraian tersebut di atas antara konsep-konsep pendidikan agama Hindu yang dijelaskan dalam berbagai pustaka suci Veda apabila digali lebih dalam, ternyata apa yang dijelaskan oleh Ki Hadjar Dewantara dengan berbagai pemikiran filosofisnya mengenai pendidikan sudah jauh dijelaskan dalam pustaka suci Veda, sehingga tulisan ini berupaya untuk menemukan titik persamaan mengenai apa yang disampaikan oleh bapak pendidikan nasional dengan apa yang terdapat dalam ajaran-ajaran agama Hindu. Menggali persamaan dalam konsep bukan berarti mendebat konsep mana yang duluan ada, namun di sini dalam arti mensinergikan antara berbagai konsep-konsep pendidikan yang yang ada untuk mewujudkan pendidikan yang harmonis, sebagaimana yang dijelaskan dalam pustaka suci Veda serta pemikiran dari Ki Hadjar Dewantara.

\section{METODE}

Metode yang digunakan dalam kajian ini adalah metode deskriptif kualitatif melalui pengamatan-pengamatan sumber-sumber (kajian pustaka) dan bahan bacaan yang terkait. Beberapa sumber bacaan yang berupa artikel jurnal ilmiah maupun tulisan dalam bentuk skripsi, buku dan lainnya penulis analisis serta mendeskripsikan terkait dengan pemikiranpemikiran filosofis konsep pendidikan dari Ki Hadjar Dewantara dengan konsep maupun sistem pendidikan dalam agama Hindu yang tertuang dalam pustaka suci Veda. Setelah beberapa sumber tersebut penulis deskripsikan selanjutnya memberikan simpulan dari keterkaitan maupun relevansinya pemikiran Ki Hadjar Dewantara dengan sistem pendidikan Hindu.

\section{HASIL DAN PEMBAHASAN}

\subsection{Teori Pendidikan Ki Hadjar Dewantara}

Pemahaman teori pendidikan di Indonesia dewasa ini menjadi menarik untuk didiskusikan. Mengapa diperlukan teori pendidikan, sebab teori pendidikan yang berlaku sekarang sudah tentu akan usang pada beberapa tahun mendatang. Pencipta pendidikan nasional dengan sistem Among adalah Ki Hadjar Dewantara. Nama lain Ki Hadjar Dewantara adalah Raden Mas Suwardi Suryaningrat, lahir pada tanggal 2 Mei 1889, setelah berumur 5 windu atau 40 tahun jawa, beliau berganti nama menjadi Ki Hadjar Dewantara tepatnya pada 23 Februari 1928. Ki Hadjar Dewantara mengajar pada perguruan Adhidarma Yogyakarta pada tahun 1922. Setahun kemudian ia mendirikan sekolah yang sesuai dengan cita-citanya sendiri, yaitu "National Onderwijs Institut Taman Siswa", kemudian berubah menjadi "Perguruan Kebangsaan Taman Siswa". Asas dari sekolah tersebut adalah (1) menjadi hak seseorang untuk mengatur dirinya sendiri, (2) pengajar harus membimbing anak menjadi manusia merdeka dalam cipta, rasa, karsa dan dalam menggunakannya untuk hidup mandiri (Neolaka, 2017: 35). 
Ki Hadjar Dewantara mungkin tepat dipandang sebagai seorang pendidik yang humanis. Rentang hidupnya sarat dengan aktivitas politik, jurnalistik dan pendidikan. Ia berambisi untuk membangun dan memajukan dimensi-dimensi kemanusiaan (kecerdasan generasi) Indonesia. Pendidikan adalah bidang yang dipandangnya tepat dijadikan landasan pembangunan kemanusiaan di Indonesia. Refleksi mendasar seputar menjadi manusia bermartabat diupayakannya dalam dan melalui kerangka yang sangat strategis untuk Indonesia pada jamannya, yakni pendidikan dan pengajaran. Dalam konteks itu pula, meski ia berkecimpung pada wilayah politik dan jurnalistik, ia kerap dipandang dan diakui orangorang pada masanya sebagai pendidik sejati. Suatu julukan yang tidak salah kalau kita cermati gagasan-gagasannya yang tertuang dalam karya-karyanya (Samho dan Yasunari, 2010: 11).

Dasar dari pendidikan dan pengajaran Ki Hadjar Dewantara bersumber dari panca dharmanya. Dasar-dasar tersebut adalah: (1) kemanusiaan, (2) kodrat hidup, (3) kebangsaan, (4) kebudayaan, dan (5) kemerdekaan/ kebebasan. Dasar kemanusiaan dikatakan bahwa, pendidikan adalah usaha kebudayaan yang bertujuan memberi tuntunan dalam perkembangan hidup jiwa raga anak. Diharapkan agar kelak dalam garis kodrat pribadinya dan dengan pengaruh segala keadaan yang mengelilingi dirinya, dapat berkembang dalam hidupnya lahir dan batin, menuju ke arah peradaban kemanusiaan. Adapun kodrat hidup pada tiap manusia menunjukkan adanya kekuatan intelektual sebagai bekal hidupnya. Kodrat hidup tersebut perlu untuk pemeliharaan dan kemajuan hidupnya, hingga lambat laun manusia dapat mencapai keselamatan dalam hidup lahir dan kebahagiaan dalam hidup batin, baik untuk pribadinya maupun untuk masyarakat.

Pendidikan nasional menurut Ki Hadjar Dewantara bermaksud menjadikan anak didik seorang nasionalis, pencinta bangsa dalam arti seorang pembawa cita-cita kebangsaan. Peserta didik wajib dibimbing agar menyempurnakan dirinya, jasmani maupun rohani, guna kepentingan dan kemajuan bangsa dan negara. Menurut Ki Hadjar Dewantara "pendidikan harus mengajak anak masuk ke dalam jiwa bangsa, yang terwujud dalam kebudayaannya, maka haruslah kebudayaan bangsa sendiri dijadikan pangkal dan tujuan pendidikan nasional".

Teori pendidikan Ki Hadjar Dewantara dapat disimpulkan bahwa kebudayaan wajib berlangsung terus sebagai suatu rantai yang makin lama makin bertambah panjang. Kebudayaan tiap angkatan merupakan mata rantai penyambung mata rantai yang terdahulu dengan mata rantai yang akan datang. Begitulah kebudayaan wajib berjalan tak terputus. Kebudayaan bukan suatu hal yang statis maupun tradisonal. Unsur-unsur kebudayaan asing diperhatikan untuk memilih (selektif). Beberapa semboyan perlambang yang digunakan agar meresap ke dalam hati manusia (peserta didik), diberikan dalam bentuk keindahan, maka semboyan atau perlambang tersebut mudah untuk diingat oleh peserta didik. Semboyan yang digunakan oleh Ki Hadjar Dewantara anatara lain:

a. Bibit, bebed, bobot, artinya: pilihan bibit sehat, berasal dari jenis baik (bebed), dan berisi (bobot).

b. Kita berhamba kepada Sang Anak, artinya: tidak murid untuk guru, melainkan guru untuk murid. 
c. Ing Ngarso Sung Tulodo, artinya di depan memberikan teladan, Ing Madyo Mangun Karso (di tengah memeberikan semangat) dan Tut Wuri Handayani (di belakang memberikan dorongan).

d. Rawe-rawe rantas, malang-malang puntung, artinya: segala sesuatu yang merintangi akan hancur (Neolaka, 2017: 37).

Ki Hadjar Dewantara mengedepankan tiga ajaran tentang pendidikan (tiga fatwa), yakni: tetep, antep dan mantep; ngandel, kandel, kendel dan bandel; Neng, ning, nung dan nang. Pertama, tetep, antep, mantep artinya bahwa pendidikan itu harus membentuk ketetapan pikiran dan batin, menjamin keyakinan diri dan membentuk kemantapan dalam prinsip hidup. Istilah tetep di sini dapat dimaknai dalam kerangka yang prinsipil, yakni memiliki ketetapan pikiran (untuk berkomitmen) yang selaras dengan nilai-nilai sosial. Pendidikan membentuk seseorang untuk mampu berpikir kritis dan memiliki ketetapan pikiran dalam khasanah nilai-nilai. Artinya, pikirannya tidak gampang terombangambingkan oleh tawaran-tawaran hidup yang tidak selaras dengan nilai-nilai. Istilah antep menunjukkan bahwa pendidikan menghantar seseorang untuk memiliki "kepercayaan diri" dan keuletan diri untuk maju terus dalam mengatasi segala tantangan kehidupan secara ksatria (bersahaja). Dalam praksis kehidupan, orang yang antep adalah yang memiliki keteguhan hati ke arah kualitas diri sebagai manusia personal dan anggota komunitas sosial. Sementara istilah mantep menunjukkan bahwa pendidikan menghantar seseorang untuk kemajuan diri, memiliki orientasi yang jelas untuk menuju tujuan yang pasti, yakni kemerdekaan diri sebagai pribadi, anggota masyarakat dan warga dunia. Jadi, landasan operasional pendidikan adalah upaya membentuk kualitas pribadi peserta didik sampai pada tingkat yang maksimal. Kira-kira begitulah makna interpretatif dari fatwa pertama Ki Hadjar tentang pendidikan (tetep, antep dan mantep).

Kedua, ngandel, kandel, kendel dan bandel. ngandel adalah istilah dalam bahasa Jawa yang artinya "berpendirian tegak". Pendidikan itu harus menghantar orang pada kondisi diri yang ngandel (berpendirian tegak/teguh). Orang yang berpendirian tegak adalah yang berprinsip dalam hidup. Kendel adalah istilah yang menunjukkan keberanian. Pendidikan membentuk seseorang untuk menjadi pribadi yang berani, berwibawa dan ksatria. Orang yang berpendidikan adalah orang yang berani menegakkan kebenaran dan keadilan, matang dan dewasa dalam menghadapi segala cobaan. Sementara istilah bandel menunjukkan bahwa orang yang terdidik adalah yang "tahan uji". Segala cobaan hidup dan dalam segala situasi hidup dihadapinya dengan sikap tawakal, tidak lekas ketakutan dan hilang nyali.

Ketiga, neng, ning, nung dan nang. Artinya bahwa pendidikan pada tataran terdalam bercorak religius. Pendidikan itu menciptakan kesenangan perasaan (neng), keheningan (ning), ketenangan (nang), dan renungan (nung). Dalam dan melalui pindidikan, seseorang bisa mengalami kesucian pikiran dan ketenangan batin. Menurut Ki Hadjar Dewantara, kekuasaan akan datang manakala seseorang sudah mengalami kesucian pikiran, ketenangan batin dan hati.

Ketiga fatwa pendidikan Ki Hadjar Dewantara di atas tetap penting sebab ia memiliki kandungan makna yang berkualitas kemanusiawian, suatu kualitas yang merupakan bagian mendasar dari idealisme pendidikan sejak masa Yunani klasik. Bila ketiga fatwa itu dikritisi, ia tampak tetap memiliki relevansi untuk konteks pendidikan Indonesia kini terutama manakala penerapannya dimaksudkan untuk membangun jiwa kepemimpinan 
dalam diri anak-anak di Indonesia. Harapan ke depan mereka kelak mampu menjadi pemimpin Indonesia yang benar-benar "meng-Indonesia". Artinya, menjadi pemimpin yang memiliki ketetapan pikiran dan batin, memiliki kepercayaan diri dan pendirian yang teguh, memiliki pikiran yang suci, batin yang tenang dan hati yang senang. Kondisi demikian menjadi jaminan ke arah terciptanya kepemimpinan yang memerdekakan kemanusiaan setiap pribadi di Indonesia secara utuh dan penuh.

\subsection{Relevansi Konsep Pendidikan Ki Hadjar Dewantara dengan Sistem Pendidikan Hindu}

Ki Hadjar Dewantara memberikan beberapa pedoman dalam menciptakan kultur positif seorang pendidik. Semboyan Trilogi pendidikan memiliki arti yang melibatkan seluruh pelaku pendidikan atau guru dan peserta didik adalah: Tut Wuri Handayani, dari belakang seorang guru harus bisa memberikan dorongan dan arahan. Ing Madya Mangun Karsa pada saat di antara peserta didik, guru harus menciptakan prakarsa dan ide. Ing Ngarsa Sung Tulada, berarti ketika guru berada di depan, seorang guru harus memberi teladan atau contoh dengan tindakan yang baik.

Menurut Ki Hadjar Dewantara mendidik dalam arti yang sesungguhnya adalah proses memanusiakan manusia, yakni pengangkatan manusia ke taraf insani. Mendidik harus lebih memerdekakan manusia dari aspek hidup batin (otonomi berpikir dan mengambil keputusan, martabat, mentalitas demokratik). Metode belajar yang diusung oleh Ki Hadjar Dewantara adalah metode among. Among memiliki makna menjaga kelangsungan hidup batin peserta didik dengan mendampingi dan mengarahkan. Bukan hanya membiarkan perkembangan batin peserta didik namun juga menjaga agar keadaan batin peserta didik tetap dalam keadaan baik. Berdasarkan pernyataan tersebut, pendidik berkewajiban mengembangkan peserta didik sesuai dengan karakter peserta didik dan karakter lingkungan budaya setempat. Hal tersebut bertujuan agar peserta didik dapat menguasai diri sendiri.

Metode among merupakan pemeliharaan dan perhatian untuk mendapat pertumbuhan anak lahir dan batin sesuai dengan kodrat. Metode among ini memiliki orientasi pendidikan ke arah siswa, atau kini lebih populer disebut student centered (Noventari, 2016: 53). Pendidik memberikan peluang bagi anak untuk mengembangkan kreatifitasnya dan inisiatif dalam menghadapi atau mengerjakan sesuatu. Pendidik tidak lepas tanggung jawab begitu saja, tetapi masih terus memantau perkembangan anak sampai anak tersebut benar-benar sudah mandiri. Inilah maksud Ki Hadjar Dewantara yang mengatakan bahwa metode among adalah metode pendidikan yang berjiwa kekeluargaan yang bersendikan kodrat alam dan kemerdekaan (Muthoifin \& Jinan, 2015: 300). Berikut adalah bentuk dan cara mendidik anak menurut Ki Hadjar Dewantara.

Tabel 1

Cara Mendidik Ki Hadjar Dewantara

\begin{tabular}{|l|l|c|}
\hline No. & \multicolumn{1}{|c|}{ Cara Mendidik } & Rentang Usia Anak \\
\hline 1 & Memberi contoh & \multirow{2}{*}{$1-7$ tahun } \\
\hline 2 & Pembiasaan & \\
\hline 3 & Pengajaran & \\
\hline
\end{tabular}




\begin{tabular}{|l|l|c|}
\hline 4 & Perintah, paksaan, hukuman & 7-14 tahun \\
\hline 5 & Laku & 14-21 tahun \\
\hline 6 & Pengalaman lahir dan batin & 14-21 \\
\hline
\end{tabular}

Sumber: (Samho, 2014: 293)

Proses dan cara mendidik anak yang disampaikan oleh Ki Hadjar Dewantara sangat relevan dan memiliki kemiripan dengan apa yang tersurat dalam kitab Niti Çastra IV. 20, yang menguraikan mengenai penjenjangan dalam pendidikan yang dilakukan kepada anak sebagai sistem dari pelaksanaan pendidikan. Hal ini dimaksudkan untuk dapat mencapai hasil pendidikan yang memuaskan. Adapun pernyataannya sebagai berikut.

“Tingkahning sutaçasaneka kadi raja tanaya ri sedeng limang tahun. Saptang warsa wara bulun sapuluhing tahun ika wuruken ring aksara. Yapwan sodaçawarsa tulya wara mitra tinaha-taha denta midane. Yan wus putra suputra tinghalana solahika wuruken ing nayenggita".

Terjemahan:

Anak yang sedang berumur lima tahun, hendaknya diperlakukan seperti anak raja; jika sudah berumur tujuh tahun, dilatih supaya suka menurut; jika sudah sepuluh tahun diajari membaca. jika sudah enam belas tahun diperlakukan sebagai sahabat; kalau kita mau menunjukkan kesalahannya, harus dengan hati-hati sekali. Jika ia sendiri sudah beranak, diamat-amati saja tingkahnya; kalau hendak memberi pelajaran kepadanya, cukup dengan gerak dan alamat.

Sistem pendidikan menurut ketentuan di atas, mengandung isyarat agar peserta didik itu benar-benar diperhatikan sesuai dengan jenjang umur (tingkat perkembangan) anak itu. Termasuk pula secara informal, orang tua sebagai pendidik di dalam kehidupan berumah tangga, harus ikut berperan juga, dalam pendekatannya harus disesuaikan dengan tingkat perkembangan anak-anaknya. Misalnya anak pada tingkat usia lima tahun, maka anak itu harus diperlakukan sebagaimana lazimnya seorang anak raja. Dalam hal ini, seorang anak tentu memperoleh perlakuan yang istimewa, dalam arti segala kehendaknya bisa dituruti. Orang tua harus melayani segala yang diperlukan anak. Demikianlah seterusnya, hingga anak mencapai masa berumah tangga, sebagaimana diungkap dalam sloka di atas. Ajaranajaran tersebut patut dijadikan pola terapan di dalam meningkatkan pembinaan dan pendidikan anak dalam keluarga.

Selain itu dalam kitab Bhagavadgìtā IV.34, menekankan tiga cara yang harus dipatuhi dalam pendidikan (belajar ilmu pengetahuan), sehingga usaha pendidikan yang dilakukan mendapatkan hasil yang optimal. Adapun uraiannya dinyatakan sebagai berikut: "Belajarlah dengan sujud disiplin, dengan bertanya dan dengan kerja berbakti, guru budiman yang melihat kebenaran akan mengajarkan padamu ilmu budi pekerti". Tiga cara belajar yang dimaksud dalam sloka di atas, merupakan proses pelaksanaan pendidikan itu sendiri yang harus ditaati sehingga mendapat hasil yang sebaik-baiknya. Cara-cara ini tidak dapat dipisahkan satu sama lain untuk mencapai tujuan pendidikan yang diharapkan. 
Adapun cara-cara yang dimaksud adalah pranipatena yaitu hormat, sujud dan disiplin kepada guru yang memberi pendidikan, papariprasnena yaitu bertanya, mencari dan memikirkan sendiri ilmu pengetahuan yang diberikan kepadanya, dan sevaya yaitu berbakti, melayani dan setia dengan tulus ikhlas kepada Guru.

Kualitas pendidikan anak menurut ajaran Hindu disebut suputra, dan hal ini banyak disebut-sebut dalam sastra agama. Di dalam Kakawin Nitisastra IV.1, dinyatakan sebagai berikut:

"Sanghyang candra taranggana pinaka dipa memadangi ri kala ning wengi; Sanghyang surya sedeng prabhasa maka dipa memadangi ri bhumi mandala; Widyasastra sudharma dipanikanang tribhuwana sumena prabhaswara; Yaning putra suputra sadhu gunawan memadangi kula wandhu wandhawa.

Terjemahan:

Bulan dan bintang memberikan penerangan di waktu malam hari; matahari bersinar menerangi bumi; ilmu pengetahun, pelajaran dan peraturan yang baik menerangi tiga jagat yang sempurna. Putra yang baik saleh dan gunawan serta pandai, membahagiakan keluarganya.

Selanjutnya dalam ajaran Agama Hindu, baik kitab suci Veda maupun susastra lainnya dikenal adanya tiga lingkungan pendidikan, yaitu keluarga, sekolah dan masyarakat (Titib, 2003: 14). Sekolah-sekolah pada jaman Veda disebut sakha atau patasala dan pada masa belakangan dikenal dengan nama Ashrama. Di Bali, di samping istilah Ashrama (kini disebut Pasraman) dikenal pula istilah katyagan (dari kata Bahasa Sanskerta, tyaga yang berarti tempat untuk melepaskan diri dari ikatan rumah untuk belajar di sekolah) sedang komponen yang memberikan pendidikan (pendidik) dikenal dengan sebutan "tri kang sinangguh guru" yang artinya tiga yang disebut guru. Adapun ketiga guru itu adalah guru rupaka, yang berada dilingkungan rumah yaitu orang tua, guru pangajian (dari kata adhyaya yang artinya belajar) yaitu guru yang memberikan pendidikan formal di sekolahsekolah, dan guru wisesa seperti pemerintah, pemukapemuka agama atau tokoh-tokoh masyarakat. Hal tersebut tentu sangat bertalian dengan konsep "Trisentral Pendidikan" yang dijelaskan oleh Ki Hadjar Dewantara.

Kegiatan pendidikan dalam Agama Hindu, dikenal dengan istilah "aguron-guron", atau "asewakadharma". Pengertian pendidikan dalam Agama Hindu, tidak akan terlepas dari kedudukan kitab Veda sebagai sumber ajaran Agama Hindu. Oleh karena itu kitab Veda dan susastra Hindu lainnya berfungsi sebagai pedoman yang menuntun manusia dalam menjalankan kegiatan sehari-hari, termasuk dalam kegiatan pendidikan. Dalam sistem pendidikan menurut Veda, anak menjadi pusat perhatian, artinya anak merupakan aset dan peserta didik yang mendapat perhatian utama. Kata anak dalam bahasa Sanskerta adalah "putra" Kata "putra" pada mulanya berarti kecil atau yang disayang, kemudian kata ini dipakai menjelaskan mengapa pentingnya seorang anak lahir dalam keluarga:

"Oleh karena seorang anak yang akan menyeberangkan orang tuanya dari neraka yang disebut put (neraka lantaran tidak memiliki keturunan). 
Bila diperhatikan dengan saksama, maka pendidikan menurut kitab suci Veda lebih menekankan pada pendidikan budi pekerti yang luhur, karena tujuan akhir dari pendidikan adalah karakter yang baik. Dengan karakter yang baik, serta kecerdasan, giat bekerja/suka bekerja keras, dan bertanggung jawab, maka seorang anak didik (sisya) akan sukses menatap masa depan mereka.

Demikianlah dapat dinyatakan bahwa ajaran suci Veda dan susastra Hindu lainnya memandang anak atau putra sebagai pusat perhatian dan kegiatan yang berkaitan dengan pendidikan. Dalam hal ini, pada umat Hindu di Bali meyakini, bahwa karakter seorang anak sangat pula ditentukan oleh kedua orang tuanya, lingkungannya dan upacara-upacara yang berkaitan dengan proses kelahiran seorang anak. Ketika seorang anak lahir, maka karakter seseorang dapat dilihat pada hari kelahirannya yang disebut Dasavara (hari yang sepuluh), yaitu: "pandita, pati, sukha, duhkha, srì, manuh, mànusa, ràja, deva, dan raksasa". Demikian pula pemberian nama kepada seorang anak, dikaitkan pula dengan karakter anak sesuai hari "dasavara” dari anak tersebut.

\section{SIMPULAN}

$\mathrm{Ki}$ Hadjar Dewantara telah mengemukakan pendapatnya mengenai "Tripusat Pendidikan", yaitu keluarga, sekolah dan masyarakat. Selain itu konsep "Trilogi Pendidikan" yang beliau jelaskan juga sangat sarat dengan makna sebagai berikut Ing Ngarso Sung Tulada (di depan memberikan teladan), Ing Madya Mangun Karsa (di tengah memberikan semangat) dan Tut Wuri Handayani (di belakang memberikan dorongan) tampak sangat memiliki keterkaitan dengan sistem pendidikan Hindu yakni sekolahsekolah pada jaman Veda disebut sakha atau patasala dan pada masa belakangan dikenal dengan nama Ashrama. Di Bali, di samping istilah Ashrama (kini disebut Pasraman) dikenal pula istilah katyagan (dari kata Bahasa Sanskerta, tyaga yang berarti tempat untuk melepaskan diri dari ikatan rumah untuk belajar di sekolah) sedang komponen yang memberikan pendidikan (pendidik) dikenal dengan sebutan "tri kang sinangguh guru" yang artinya tiga yang disebut guru. Selain itu konsep among Ki Hadjar Dewantara sangat memiliki persamaan dengan yang dijelaskan dalam pustaka suci Veda.

\section{DAFTAR PUSTAKA}

Muthoifin, \& Jinan, M. 2015. Pendidikan Karakter Ki Hadjar Dewantara: Studi Kritis Pemikiran Karakter Dan Budi Pekerti Dalam Tinjauan Islam. Profetika.

Neolaka, Amos \& Grace Amialia. 2017. Landasan Pendidikan Dasar Pengendalian Diri Sendiri Menuju Perubahan Hidup. Prenada Media Group: Jakarta.

Noventari, Widya. 2016. Kajian Konsep dan Praktek Sistem Pendidikan Taman Siswa sesuai dengan Alam Pemikiran Ki Hadjar Dewantara. Fakultas Keguruan dan Ilmu Pendidikan: Universitas Sebelas Maret.

Samho, Bartolomeu dan Oscar Yasonari. 2010. Konsep Pendidikan Ki Hadjar Dewantara dan Tantangan-Tantangan Implementasinya di Indonesia Dewasa ini. Bandung: LPPM Universitas Katolik Parahyangan. 
Samho, B. 2014. Pendidikan Karakter Dalam Kultur Globalisasi: Inspirasi Dari Ki Hadjar Dewantara. Melintas: Bandung.

Tilaar. H.A.R. 2015. Pedagogik Teoretis untuk Indonesia. PT Kompas Media Nusantara: Jakarta.

Titib, I Made. 2003. Menumbuhkembangkan Pendidikan Budi Pekerti pada Anak. Ganeça Exact: Bandung.

Wiana, I Ketut. 1997. Cara Belajar Agama Hindu yang Baik. Yayasan Dharma Narada: Denpasar. 